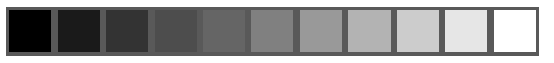

\title{
Causalidade e representação em Berkeley: Os dados imediatos da subjetividade
}

\section{Pablo Enrique Abraham Zunino*}

Resumo: O objetivo deste artigo é examinar a relação entre ser e perceber a partir da análise do princípio central da filosofia de George Berkeley — esse est percipi ${ }^{1}$ —, conforme é apresentado na obra $A$ treatise concerning the principles of human knowledge (1710). Para desenvolver essa análise e seguindo o tratamento dado por Grayling ${ }^{2}$ à fundamentação desse princípio, pretendemos mostrar que os argumentos de Berkeley se dispõem em três níveis: o estritamente empírico (sense data); o fenomênico (mundo da experiência ordinária); e o metafísico que, em última instância, explica os dois anteriores.

Palavras chave: Berkeley, percepção, idéia, espírito, realidade, aparência.

\begin{abstract}
The paper aims to examine the relation between to be and to perceive starting from the analysis of George Berkeley's central principle - esse est percipi - , as it is introduced by the author in $A$ treatise concerning the principles of human knowledge (1710). To develop our analysis we will follow the treatment Grayling offers on the fundamentation of this principle and we intend to show that Berkeley's arguments are organized in three levels: the strictly empirical level (sense data); the phenomenal level (the world of ordinary experience); and the metaphysical level that explains the two former cases.
\end{abstract}

Keywords: Berkeley, perception, idea, spirit, reality, appearance.

\footnotetext{
* Doutorando do Departamento de Filosofia da USP e bolsista do CNPq.
} 

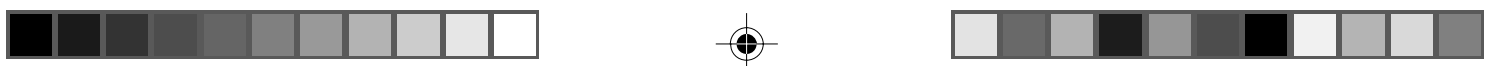

CAdernos Espinosanos XVI - 2007

"Nihil est in intellectu quod non prius fuit in sensu." ${ }_{3}$

\section{I - Identificação entre idéia e objeto sensível.}

Nos primeiros parágrafos dos Principles ( §§ 1-7), Berkeley apresenta sucintamente sua filosofia, deixando o leitor em estado de choque $^{4}$ ao constatar que:

"Algumas verdades são tão próximas e óbvias para a mente, que um homem só precisaria abrir seus olhos para vê-las. Assim me parece que é esta, a saber, que todo o coro do firmamento e a mobília da terra, numa palavra, todos esses corpos que compõem a poderosa estrutura do mundo, não têm nenhuma existência sem uma mente, pois seu ser é ser percebido ou conhecido". 5

Não obstante, quando refletimos sobre essa passagem, facilmente a interpretamos de maneira equivocada. Para evitar isso, devemos distinguir os dois elementos que compõem a teoria da percepção de Berkeley, isto é, espírito e idéia. Desse modo, o problema lembra a formulação cartesiana da relação entre sujeito e objeto, mas a chave para resolvê-lo está no sentido peculiar que Berkeley confere ao termo "idéia", tomando como ponto de partida a definição de idéia de Locke: "Seja lá o que a mente percebe em si mesma, ou é o objeto imediato da percepção, pensamento, ou entendimento, a isso eu chamo de idéia". ${ }^{6}$ Nesse sentido, a classificação de idéias com a qual Berkeley inaugura sua obra pretende dar conta de tudo aquilo que possa ser considerado como objeto do conhecimento humano: 

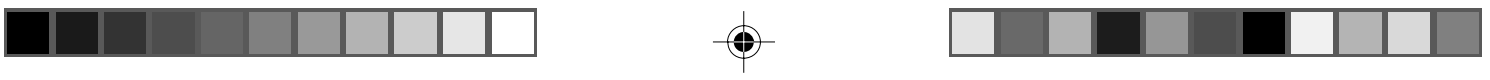

Pablo Enrique Abraham Zunino

"É evidente a quem investiga o objeto do conhecimento humano haver idéias (1) atualmente impressas nos sentidos, ou (2) percebidas considerando as paixões e operações do espirito, ou finalmente (3) formadas com o auxílio da memória e da imaginação, compondo, dividindo, ou simplesmente representando as originariamente apreendidas pelo modo acima referido". 7

Uma via de interpretação errada dessa classificação de idéias poderia sugerir que, para Berkeley, não há como distinguir as idéias reais das idéias da imaginação. ${ }^{8} \mathrm{~A}$ dor que sentimos ao queimar-nos com fogo, por exemplo, não tem a mesma intensidade que a lembrança dessa dor. Obviamente, podemos imaginar a dor de uma queimadura, mas isso ocorre necessariamente em virtude da idéia original de dor que percebemos através do sentido do tato. Em vista disso, observa Winkler ${ }^{9}$, as idéias impressas nos sentidos diferem das idéias excitadas pela imaginação por serem mais fortes, mais ordenadas e mais coerentes. "Mas mesmo assim, são idéias", diz Berkeley, adotando um uso restrito do termo "idéia" que se aplica exclusivamente no caso das idéias da imaginação:

"As idéias impressas nos sentidos pelo Autor da Natureza são chamadas coisas reais; e aquelas excitadas na imaginação, por ser menos regulares, vivas e constantes, são denominadas mais apropriadamente de idéias, ou imagens das coisas, que copiam e representam". 10

A partir dessa restrição, podemos compreender a distinção entre apresentação e representação de idéias que $\mathrm{Smith}^{11}$ destaca no contexto 
do cartesianismo. Segundo ele, a reviravolta metafísica do sistema de Berkeley é uma questão de pura consistência, levando-se em conta que a noção central de representação foi completamente alterada. Vale lembrar que a essência da representação era a distinção ontológica entre o representante (representans) e o representado (representatum). Todavia, quando procuramos as características materiais das representações mentais (representantia), o que encontramos são as sensações, e ao aprofundar ainda mais a investigação, identificamos as características próprias do que é representado (representata) também nas sensações. Eis por que Berkeley pretende abolir a maneira clássica de se entender a noção de representação. Os estados mentais não são mais intrinsecamente representações, mas apresentações. Falar em apresentação de idéias, portanto, significa que as idéias se apresentam à mente, independentemente da nossa vontade: abrimos os olhos $\mathrm{e}$, simplesmente, as idéias são percebidas. A representação de idéias, por sua vez, supõe uma re-apresentação daquelas idéias que, em algum momento anterior, foram imediatamente percebidas pelos sentidos. As quimeras, por exemplo, são imagens formadas em nossa mente com o auxílio da memória e da imaginação; elas apenas re-apresentam idéias primitivas ou suas partes, combinadas entre si:

"Acho que tenho a faculdade de imaginar, conceber ou representar-me para mim mesmo as idéias dessas coisas particulares que já percebi, compondo-as e dividindo-as de vários modos. Posso imaginar um homem com duas cabeças, ou a parte superior de um homem unida com o corpo de um cavalo". ${ }^{12}$

Tanto para o senso comum como para os filósofos, Berkeley está certo quando diz que esse tipo de idéias (centauro, sereia) existe 
apenas na mente que as percebe, precisamente porque se trata do fruto da nossa imaginação. Porém, a condição ontológica de ser somente enquanto objeto percebido é negada ao grupo de idéias atualmente impressas nos sentidos, alegando-se que, nesse caso, tratar-se-ia de "objetos materiais" que existem fora da mente, ou seja, em um suposto espaço exterior. Berkeley, por sua vez, vai mostrar que os objetos sensíveis são percebidos como coleções de idéias ou feixes de percepções, de modo que não precisamos supor uma materialidade ou exterioridade subjacente. Essa é uma tese contrária à duplicação do mundo como realidade e como aparência, pois dissolve a bipartição que estabelece, de um lado, a realidade das coisas materiais e exteriores e, de outro, o caráter aparente das idéias enquanto imagens ou cópias das coisas reais. Com esta redução dos objetos a coleções de idéias, Berkeley visa superar o dualismo espírito-matéria e a ilusão de que haveria uma substância material unificando diferentes qualidades sensíveis (sensações), que pertencem a um mesmo objeto. Em vista disso, a crítica da idéia geral abstrata constitui o principal argumento de Berkeley contra os que defendem a existência da matéria, assimilando a substância material à idéia do ser em geral:

"Se interrogarmos sobre isto os melhores filósofos, veremos que estão de acordo em atribuir à substância material apenas o sentido do ser em geral, juntamente com a noção relativa de suporte de acidentes. A idéia geral do Ser parece-me a mais abstrata e incompreensível de todas $"{ }^{13}$

Não vamos aprofundar essa crítica aqui ${ }^{14}$, entretanto, devemos nos deter num ponto que certamente proporcionará uma compreensão mais nítida da teoria das idéias que pretendemos esclarecer neste 

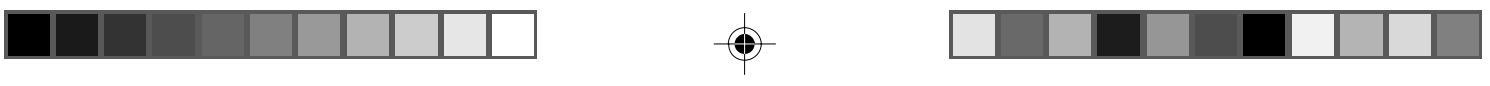

Cadernos Espinosanos XVI - 2007

trabalho, a saber, a recusa berkeleyana da distinção entre qualidades primárias e secundárias. Essa distinção, na verdade, deriva da filosofia corpuscular e parte da aceitação de que "o mundo é constituído por uma inumerável multidão de corpúsculos singulares insensiveis providos com seus próprios tamanhos, formas e movimentos". Se o universo fosse aniquilado, excetuando-se completamente todos esses corpúsculos indivisíveis e, portanto, não houvesse mais consciência das coisas materiais, restaria somente "matéria, movimento (ou repouso), volume e forma". Deus criou o mundo e comunicou o movimento aos componentes materiais, de maneira que "para explicar fenômenos particulares" precisamos considerar apenas "o tamanho, a forma, o movimento (ou a intenção de), a textura e as qualidades resultantes das pequenas partículas de matéria". As qualidades secundárias, entretanto, são dependentes das "mais simples e primitivas afecções da matéria", ao passo que a sensação é o efeito dos corpúsculos impressionando (strike on) os órgãos dos sentidos e excitando movimentos que são comunicados ao cérebro, onde dão lugar à percepção. ${ }^{15}$

Essa teoria, que articula as concepções fundamentais da ciência moderna, era amplamente aceitada por Locke, que distingue as qualidades primárias de solidez, extensão, figura, movimento ou repouso e número tendo em vista a sua impenetrabilidade, isto é, a ocupação exclusiva de um certo lugar. Locke afirma que essas qualidades são inseparáveis dos corpos, ao passo que as qualidades secundárias (cores, sons, cheiros e sabores), não são "nada nos próprios objetos, mas poderes para produzir várias sensações em nós por suas qualidades primárias". ${ }^{16}$ Além disso, devemos levar em conta a maneira como conhecemos essas qualidades (primárias e 
secundárias) e a descrição do nosso contato com os corpos, conforme a explicação que Locke herdou de Boyle:

“(...) percebemos essas qualidades originais em tais [objetos exteriores], impressionando separadamente nossos sentidos, [pois] algum movimento deve ser transmitido pelos nossos nervos (...) até o cérebro ou sede da sensação, para produzir em nossa mente as idéias particulares que temos deles". ${ }^{17}$

Em relação à percepção sensível, Locke afirma que as idéias são causadas por objetos exteriores, que de certa forma representam para nós esses objetos. ${ }^{18}$ Desse modo, nossas idéias correspondem (agree) e assemelham-se (resemble) aos objetos em suas qualidades primárias, que causam em nós a percepção das qualidades secundárias. ${ }^{19}$ Poderíamos dizer que existe uma diferença de valor objetivo entre as percepções que representam as qualidades primárias e as que representam as qualidades secundárias, visto que as primeiras representam efetivamente os objetos e, portanto, nos conduzem à realidade exterior, enquanto as outras não:

"As idéias das qualidades primárias dos corpos são imagens (resemblances) deles e seus padrões (patterns) existem de fato nos próprios corpos, mas as idéias produzidas em nós por essas qualidades secundárias não têm nenhuma semelhança com eles. Não há nada como nossas idéias existindo nos próprios corpos". ${ }^{20}$

Em nenhum caso nós temos acesso direto aos objetos, dado que nossas idéias são efeitos do término de cadeias causais. Isso 
demonstra que percepção, para Locke, é sempre uma mediação ou representação. Entretanto, a distinção entre qualidades primárias e secundárias estabelece um limite entre a parte objetiva da percepção e a parte subjetiva. Ainda que nossas idéias, enquanto percepções, não estejam nos próprios objetos, existe uma parte delas (as qualidades primárias de solidez, extensão, figura, movimento e número), cuja causa está no objeto exterior, isto é, na substância material e constitui o componente objetivo da percepção. Em contrapartida, as qualidades secundárias são o componente subjetivo da percepção, já que existem apenas na mente e não são causadas diretamente pelos objetos, mas por certos poderes que eles possuem. Zaterka ${ }^{21}$ descreve esses poderes como "mudanças que os corpos podem produzir em outros corpos" ou "efeitos que os corpos produzem em nós". De qualquer modo, vimos que Berkeley concebe os corpos como 'coleções de idéias', sendo incompreensível que estas se invistam de algum poder:

“Um pouco de atenção nos mostrará que o ser de uma idéia implica a sua passividade e inércia, tal que é impossível a idéia fazer seja o que for, ou, estritamente falando, ser causa de alguma coisa; nem pode ser semelhança (resemblance) ou modelo (pattern) de um ser ativo (...). De onde não poderem extensão, figura e movimento ser causa de sensações nossas. Dizer, portanto, que elas são efeito de forças resultantes de configuração, número, movimento e forma de corpúsculos é decerto falso. ${ }^{22}$

Berkeley pretende dissolver a distinção entre qualidades primárias e secundárias por meio de dois argumentos: o primeiro $-a$ 
passividade das idéias — consiste em mostrar que não podemos estabelecer relações de causalidade entre idéias, porque nenhuma delas têm o poder de alterar outra. As idéias são todas inertes, de sorte que não podemos atribuir-lhes atividade nem encontrar nelas qualquer tipo de força. A relação que podemos estabelecer entre as idéias é sempre mediada pelo espírito, isto é, pela significação que as percepções adquirem para nós enquanto símbolos de conjunções constantes observadas com certa regularidade no curso da Natureza:

“(...) a conexão das idéias não implica a relação de causa e efeito, mas somente a de um sinal da coisa significada. O fogo que vejo não é causa da dor sentida se me aproximar, mas o sinal para me acautelar dele. $O$ ruído que ouço não é efeito do movimento ou colisão de corpos externos, mas o sinal disso". ${ }^{23}$

O segundo argumento — a semelhança entre idéias — visa refutar a teoria da representação, isto é, a suposição de que nossas idéias representam coisas exteriores semelhantes a elas, que existem numa substância material imperceptível, independentemente do espírito. Berkeley sustenta que uma idéia só pode ser semelhante a outra idéia, ou seja, uma cor pode assemelhar-se a outra cor, uma forma a outra, etc. Ora, como poderia uma idéia ser semelhante a outra coisa diferente dela? Se é possível perceber os supostos 'originais', alega ele, deve ser porque também são idéias. Porém, se não podemos percebê-los, não teria sentido afirmar que uma cor é semelhante a uma coisa invisível, ou que o áspero se assemelha a uma coisa intangível? ${ }^{24}$ Logo, as qualidades primárias (extensão, figura, movimento, etc.) não podem ser a causa das qualidades secundárias 

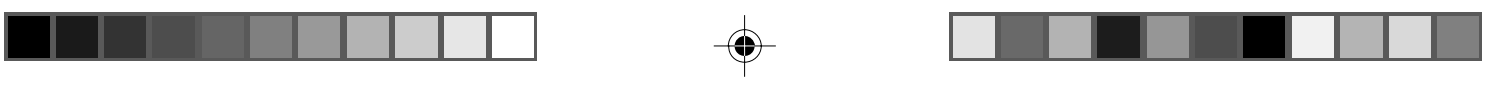

CAdernos Espinosanos XVI - 2007

(nossas sensações), nem podem existir como corpúsculos imperceptíveis, pois isso em nada se assemelha às nossas idéias:

"Eu vejo evidentemente que não está em meu poder formar uma idéia de um corpo extenso e em movimento, sem dar-lhe alguma cor ou outra qualidade sensivel das que se reconhece existirem apenas na mente. Em resumo, extensão, figura, e movimento, abstraídos de todas as outras qualidades, são inconcebíveis. Onde existam portanto as outras qualidades sensíveis, essas devem existir também, a saber, na mente e em nenhuma outra parte", ${ }^{25}$

A passagem acima mostra que todas as qualidades, primárias e secundárias, dependem em última instância do espírito, na medida em que todas elas são idéias e, portanto, só existem enquanto objetos percebidos pela mente. Sendo assim, podemos enumerar três características principais da argumentação de Berkeley: (1) inseparabilidade entre as qualidades primárias e secundárias: uma figura aparece sempre junto com alguma cor; (2) relatividade das qualidades primárias: o tamanho dos objetos e a velocidade dos seus movimentos mudam conforme a posição do sujeito; (3) as qualidades primárias não podem ser encontradas no mundo da experiência sensível. Quando vemos objetos à distância, por exemplo, pensamos que realmente percebemos pela visão sua forma e o espaço exterior, mas Berkeley vai mostrar que não é assim que acontece. ${ }^{26}$

Diferentemente de Locke, cuja análise da substância material e da distinção entre qualidades primárias e secundárias sugere que o autor aceita um tipo de teoria causal da percepção, Berkeley, por sua 
vez, julga que os conteúdos dos nossos estados de consciência não são terminações de cadeias causais iniciadas pelas propriedades dos objetos exteriores ${ }^{27}$ Examinemos brevemente uma teoria causal desse tipo, tomando como exemplo o sentido da visão. A teoria afirma que a luz é absorvida pela superfície dos objetos, que logo a refletem com um comprimento de onda determinado. Depois, a luz percorre o "meio de intervenção" até a superfície do olho e passa através da lente, onde é focalizada sobre a retina, estimulando vários receptores em padrões codificados e transmitidos pelo nervo óptico aos centros visuais do córtex, situado na parte posterior do cérebro. O rápido estímulo das células corticais finalmente produz - de alguma forma ainda desconhecida - a idéia sensorial de uma figura colorida. ${ }^{28} \mathrm{O}$ argumento de Berkeley é que nós só temos consciência da idéia sensível que aparece no final dessa descrição; não temos acesso aos elos intermediários da cadeia causal nem a sua origem. E muito menos a qualquer coisa que escape e nos permita detectar, além das nossas idéias sensíveis, os demais eventos envolvidos na produção dessas idéias. Esta teoria, evidentemente, constitui um modelo que pretende dar conta da percepção, justificando a crença de que por meio desse processo nós temos acesso aos objetos exteriores.

Ora, tudo o que nós temos são apenas dados, que provêm das nossas idéias sensíveis (sense data). E mesmo quando não há nenhum término nas cadeias causais, como ocorre nos sonhos, nós ainda assim podemos ter essas idéias. Portanto, não temos nenhuma justificativa para usar as "premissas realistas" que a teoria causal exige a fim de estabelecer-se a si mesma. 

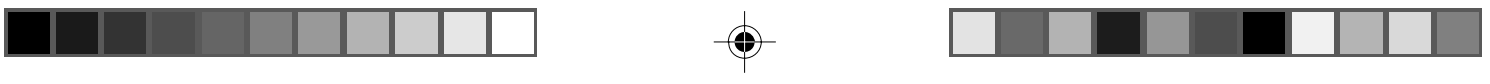

CAdernos Espinosanos XVI - 2007

\section{II - Os dados dos sentidos (sense data)}

A teoria berkeleyana das idéias pretende definir, em primeiro lugar, o que é um "objeto imediato da percepção", examinando a maneira como ele é percebido, isto é, atualmente, imediatamente $e$ propriamente. Tipton ${ }^{29}$ observa que essa formulação pode estar associada ao conceito aristotélico de "sensível próprio"30 porém o que Aristóteles chama de "sensível comum", segundo Berkeley, não é um objeto propriamente percebido pelos sentidos, mas construído pela experiência, que estabelece associações entre "idéias" percebidas por diferentes sentidos. Em vista disso, Grayling faz uma analogia entre os conceitos aristotélicos e a distinção entre qualidades primárias e secundárias:

“As qualidades primárias podem ser pensadas como sendo os 'sensíveis comuns' no sentido aristotélico, ou seja, aquilo que está disponível para mais de uma modalidade sensorial, enquanto as qualidades secundárias são os 'sensíveis próprios', disponíveis apenas para uma modalidade só". ${ }^{31}$

Aristóteles afirma que o objeto tem em ato certas qualidades e que a sensibilidade tem em potência essas propriedades. Quando ocorre o contato entre o objeto e a alma, a sensibilidade atualiza essa potencialidade, determinando para cada sentido o objeto que lhe é próprio, ou seja, aquele objeto que cada sentido é capaz de perceber. Em Berkeley, a estrutura da percepção é diferente porque não há distinção entre objeto e idéia. A idéia já é a própria atualização e a potencialidade provém do espírito, que tem capacidade de perceber. Portanto, não se trata de objetos prontos e acabados, como em 
Aristóteles, mas de "objetos sensíveis", visto que o sujeito atualiza a idéia quando ocorre a percepção.

Berkeley supõe que as idéias são "impressas" no espírito humano pelo Espírito Divino - Deus, que é Ato Puro. Por conseguinte, quando o espírito humano percebe idéias, estas são imediatamente percebidas. A originalidade de Berkeley consiste em reconhecer o valor objetivo da percepção sensível:

"Pela vista tenho idéias de luzes e cores, e respectivos tons e variantes. Pelo tato percebo o áspero e o macio, quente e frio, movimento e resistência, e de todos estes a maior ou menor quantidade ou grau. O olfato fornece-me aromas, o paladar sabores, e o ouvido traz ao espírito os sons na variedade de tom e composição. E, como vários deles se observam em conjunto, indicam-se por um nome e consideram-se uma coisa. Por exemplo, um certo sabor, cheiro, cor, forma e consistência observados juntamente são tidos como uma coisa, significada pelo nome 'maçã'. Outras coleções de idéias constituem uma pedra, uma árvore, um livro, etc., e, como são agradáveis ou desagradáveis, excitam as paixões de amor, alegria, repugnância, tristeza e assim por diante", ${ }^{32}$

O conceito singular de "idéia" e a concepção de "coleções de idéias", em Berkeley, obedece à escolha de uma argumentação que permita dar conta do existente, acentuando o caráter central da percepção, com o firme propósito de superar as tendências céticas da filosofia moderna. Todavia, há quem diga: "se o preço para refutar o ceticismo é jogar o mundo exterior para dentro da mente; é um preço

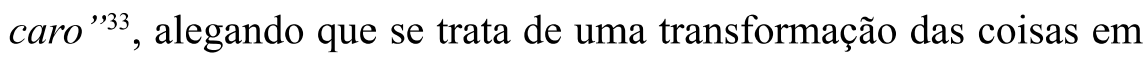


idéias ou, como interpretara $\mathrm{Kant}^{34}$, de uma degradação dos corpos à mera ilusão. Entretanto, Gueroult vai mostrar que esse é apenas o primeiro passo, já que a compreensão completa da filosofia de Berkeley envolve dois caminhos ou momentos inseparáveis: (1) a transformação de objetos em idéias, que deu lugar às críticas mais habituais entre filósofos e comentadores; e (2) a transformação de idéias em objetos, que devolve a transcendência aos objetos e, freqüentemente, é ignorada pelos críticos. ${ }^{35}$ De qualquer forma, o termo "transformação" não nos parece o mais apropriado, visto que não se trata de coisas heterogêneas, pelo contrário, o que Berkeley quer mostrar é que o sentido do termo "idéia", uma vez assimilado à percepção, é incompatível com a existência de objetos independentes da mente, ou seja, "insensíveis" ou "imperceptíveis". Nesse sentido, a identificação entre "idéia" e "objeto sensível" é o que nos leva a atribuir realidade às nossas próprias percepções:

"Por objeto sensivel entendo aquilo que é propriamente percebido pelos sentidos. Coisas propriamente percebidas pelos sentidos são imediatamente percebidas. (...) Os objetos dos sentidos, sendo coisas imediatamente percebidas são, entretanto, chamados de idéias". ${ }^{36}$

Do ponto de vista estritamente fenomênico, as idéias que correspondem a cada sentido são diferentes, tanto qualitativamente quanto quantitativamente. A sensação que eu tenho quando vejo a cor vermelha de uma maçã é completamente diferente da sensação que eu experimento na boca ao mordê-la - o gosto. Nesse sentido, trata-se de duas idéias e, portanto, de dois objetos diferentes. A sensação que eu tenho ao olhar a maçã desde um ângulo diferente não é a mesma 
que eu tive numa experiência visual anterior, portanto, a primeira idéia é distinta da segunda. O que acontece é que essas idéias aparecem constantemente unidas e, portanto, podemos legitimamente referirnos a elas como uma e a mesma coisa. Caberia um último exemplo, no sentido de elucidar o que Berkeley entende por "objeto imediato", independentemente do "objeto físico" ou do "nome" ao qual tenha sido vinculado no curso ordinário da experiência. Não é relevante se a idéia que eu percebo atualmente é alguma coisa além do que se apresenta a minha mente. $O$ fato de ser uma idéia percebida é suficiente. Por exemplo, quando viajamos de dia por uma estrada asfaltada e vemos um trecho resplandecente na pista, sempre alguns quilômetros à frente. Podemos duvidar daquilo que vemos — é uma miragem ou uma poça de água? - , mas não podemos negar que vemos o resplendor. Isso é um objeto imediato da percepção. ${ }^{37}$

As idéias do grupo (2) - percebidas considerando as paixões e operações do espírito - não são enumeradas por Berkeley. Essa denominação, no entanto, corresponde à distinção lockeana entre idéias de sensação, que são as qualidades sensíveis e idéias de reflexão, que são aquelas operações que:

“(...) suprem o entendimento com outra série de idéias que não poderia ser obtida das coisas externas, tais como a percepção, o pensamento, o duvidar, o crer, o raciocinar, o conhecer, o querer e todos os diferentes atos de nossas próprias mentes. (...) O termo operações é usado aqui em sentido lato, compreendendo não apenas as ações da mente sobre suas idéias, mas também certos tipos de paixões que às vezes nascem delas, tais como a satisfação ou inquietude que nascem de qualquer pensamento". ${ }^{38}$ 
Alguns comentadores (Tipton e Luce) julgam que Berkeley tenha incluído diplomaticamente esse grupo (2) de idéias para adaptarse ao leitor lockeano ${ }^{39}$, que encontra, logo no parágrafo inaugural da obra, uma classificação de idéias familiar. Grayling, no entanto, enfatiza que o sentido berkeleyano do termo "idéia" é incompatível com a expressão "operações do espírito", visto que essa última noção supõe uma atividade que só pode ser atribuída à mente e não às idéias em si mesmas. Com efeito, Berkeley introduz um segundo componente da teoria da percepção, no $\S 2$ dos Principles:

"Mas ao lado da infinita variedade de idéias ou objetos do conhecimento há alguma coisa que os conhece ou percebe, e realiza diversas operações como querer, imaginar, recordar, a respeito deles. Este percipiente (perceiving) ser ativo, é o que chamo de mente, espírito, alma ou eu (my self). Por estas palavras não designo alguma de minhas idéias, mas alguma coisa distinta delas e onde elas existem, ou o que é o mesmo, por que são percebidas; porque a existência de uma idéia consiste em ser percebida". ${ }^{40}$

A teoria da percepção de Berkeley tem ainda um alcance metafísico, já que para o autor o conhecimento do ser se dá por meio da identificação entre ser e perceber. Berkeley define a existência com duas modalidades de ser, radicalmente opostas entre si, que articulam a relação sujeito-objeto: o "ser percebido" (percipi), que tem caráter passivo e define às idéias enquanto objeto do conhecimento humano; e o "perceber" (percipere ${ }^{4 l}$ ), que tem caráter ativo e designa ao espírito ou sujeito. 


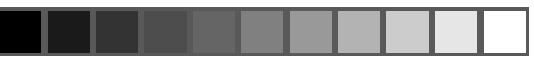

\section{III - Objetividade e Causalidade}

Ao afirmar essas duas modalidades de ser, Berkeley nega a existência absoluta de "coisas fora do espírito" ou "não-percebidas" por nenhuma mente. Dizer que "houve um som", por exemplo, significa que alguém o ouviu, pois como poderia existir de outro modo? ${ }^{42}$ Os dados dos sentidos (sense data) são idéias inertes percebidas por um elemento ativo - a mente —, portanto não devemos pensar que o sujeito está apreendendo dados que estão fora dele. A idéia de objeto sensível "exterior" não faz sentido para Berkeley, visto que "objeto sensível" é aquilo que se assimila no "interior" do sujeito. Isso não significa que haja uma redução ontológica à dimensão subjetiva do ser, mas a necessidade de pensar a relação sujeito-objeto circunscrita ao sujeito. O espírito, que é o modo subjetivo do ser, não pode perceberse a si mesmo; apenas perceber idéias, que constituem o modo objetivo do ser:

“(...) as palavras vontade, alma, espírito não significam idéias diferentes nem, na verdade, idéia alguma, senão algo diferente das idéias e que, sendo agente, não pode ser semelhante a ou representado por uma idéia qualquer". 43

Devido à irredutibilidade entre "objeto percebido" e "sujeito percipiente", não podemos conhecer diretamente o espírito, pois isso seria "ter uma idéia" do ser ativo. Para referir-se ao espírito, Berkeley adota o termo "noção" 44 , evitando a ambigüidade entre "espírito" e "idéia". Além disso, o conceito de "Espírito" é atribuído sobretudo a Deus. Nesse sentido, Grayling destaca que as "noções": 

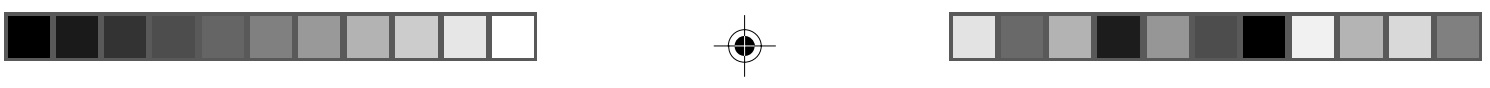

CAdernos Espinosanos XVI - 2007

“(...) são conceitos focalizados do eu (self), espírito ou mente, e de Deus, que não têm origem na experiência sensivel e, portanto, não são idéias, mas conseguimos ter uma compreensão deles por meio de uma intuição imediata, no caso da nossa própria mente, ou por 'reflexão e raciocínio', no caso de Deus". ${ }^{45}$

$\mathrm{Na}$ teoria do conhecimento de Berkeley, o sujeito não pode "ser percebido", pois se assim fosse, tornar-se-ia "objeto". Como vimos, Berkeley estabelece uma relação metafísica entre dois elementos: o elemento ativo, que é a mente; e o elemento passivo, que é a "sucessão de idéias" cuja existência consiste em ser percebida esse est percipi. Trata-se de uma objetividade inerente ao sujeito com a qual Berkeley pretende superar o dualismo cartesiano (res cogitans - res extensa). O que isso quer dizer? Quer dizer que o sujeito não pode ser objeto, visto que não podemos ter uma idéia do nosso próprio espírito nem de qualquer outro espírito humano, ou mesmo divino. Por isso, Berkeley adota o termo "noção" para referir-se à mente, porque nós podemos ter uma noção do espírito, mas não uma idéia em sentido pleno. Entretanto, o sujeito só pode conceber-se como objeto no ato da percepção. Esse é o alicerce da singularidade da auto-consciência que distingue qualitativamente a percepção que tem o espírito de si mesmo, da percepção que tem sempre uma referência objetiva, ou seja, um conteúdo objetivo. Todavia, as idéias que constituem a realidade não dependem da nossa vontade. Elas surgem de um modo próprio, o que denota a independência do curso da natureza. Essas idéias são criadas por Deus dentro do sujeito como modificações do espírito. Por conseguinte, o valor objetivo das idéias é imanente a elas. Tendo em vista que as idéias não dependem daquilo que representam, a objetividade é intrínseca ao espírito. O que garante 
essa objetividade é a concepção de uma causalidade metafísica, isto é, a Criação Divina de idéias, que estabelece uma ordem de percepções para cada mente humana, portanto, o que muda é a perspectiva de cada espírito. Assim, a existência de qualquer idéia consiste em "ser percebida" por alguma mente, mas não necessariamente a minha:

"Dizer que os corpos não têm existência fora do espirito (without the mind), não quer dizer neste ou naquele espirito particular, mas em todos. Não se segue, portanto, desses princípios que os corpos sejam aniquilados em cada instante ou não existam no intervalo das nossas percepções". ${ }^{46}$

A nossa própria consciência interna da percepção de idéias e a ordem, independente da nossa vontade, com a qual elas estão "conectadas", nos permite compreender a existência do espírito como uma "noção". Quando levantamos um braço, por exemplo, somos conscientes de que por um ato da nossa vontade realizamos essa ação. De maneira análoga, intuímos a presença divina como uma "Vontade Universal":

“Ao passo que um conjunto de idéias denota um espírito humano particular, para qualquer lado que olhemos vemos sempre e em toda parte indicios da divindade. Tudo quanto vemos, ouvimos, sentimos ou percebemos de qualquer modo pelos sentidos é sinal ou efeito do poder de Deus; como é a nossa percepção dos movimentos produzidos pelo homem". ${ }^{47}$

Todo o esforço intelectual de Berkeley visa manifestar a "imanência" da divindade, pois a afirmação de que os objetos sensíveis dependem da mente completa-se quando a existência de Deus é 
provada. Não se trata de demonstrar geometricamente sua existência, mas de compreender intuitivamente que o mundo percebido, em termos de idéias, implica uma concepção de Deus, não apenas como criador do mundo natural, mas como um Ser vitalmente envolvido com tudo o que acontece no mundo ${ }^{48}$ :

"Parece, pois, evidente a uma simples reflexão a existência de Deus ou um Espírito intimamente presente ao nosso, onde produz toda a variedade de idéias ou sensações experimentadas, e de quem dependemos absolutamente, em suma, em quem vivemos, nos movemos e somos". 49

O percurso de Berkeley, que começa com uma análise da percepção, culmina também na percepção, pois o mundo real é o mundo da experiência. A forma sensível do mundo é dada pela nossa própria estrutura perceptiva, mas não pode sobreviver sem o espírito que, por sua vez, depende de um princípio vital, isto é, Deus.

\section{Considerações Finais}

Uma das preocupações deste artigo foi mostrar que, apesar de ser considerado um autor dogmático, Berkeley leva a sério o projeto de não duplicar o ser, combatendo o ceticismo em defesa do senso comum. O problema pode ser formulado com a seguinte pergunta: “Será que o que eu vejo é real?" Berkeley responde a essa pergunta de maneira contundente: não há nenhuma realidade por trás do que nos aparece, porém essa afirmação pode ser recusada como pura 
subjetividade. No entanto, uma compreensão adequada das teses de Berkeley reconheceria uma alternativa para essa leitura precipitada. De maneira análoga a Descartes, Berkeley concebe um Deus que garante a objetividade, devolvendo a realidade das coisas ao mundo espiritual.

Por meio do conceito de "idéia", Berkeley pretende superar o problema da oposição entre realidade e aparência, identificando a percepção ao seu conteúdo, ou seja, as idéias percebidas pelos sentidos (visão, tato, olfato, etc.) aos objetos sensíveis (cores, sons, cheiros, etc.). Desse modo, o autor distingue as construções imaginativas (plano do senso comum) das construções instrumentais (plano da ciência matematizada). Ao assumir essa distinção, nos deparamos com outro problema, que consiste em determinar o estatuto do "corpo físico", tendo em vista que os conceitos utilizados pela ciência para descrever a realidade são qualitativamente diferentes da sua aparência sensível. Os corpos físicos, segundo Berkeley, têm existência enquanto "coleções de idéias" ou conjuntos de percepções. Mas o que isso significa? Significa que, imaginativamente, concebemos objetos construídos (mesas, livros, etc.), aos quais podemos atribuir-lhes realidade, isto é, construções mentais (idéias) baseadas em dados dos sentidos — sense data. Portanto, Berkeley afirma que a percepção é real, ao passo que os conceitos matemáticos são palavras adotadas pela ciência para descrever a realidade, em vista de sua utilidade instrumental. O nome é o que nos dá a ilusão da unidade, pois aquilo que chamamos de "objeto" não é mais do que as percepções sensíveis associadas pela experiência e unificadas sob um mesmo nome. Considerando que uma boa análise da experiência deveria valorizar os objetos sensíveis, percebidos independentemente uns dos outros, enquanto objetos heterogêneos, podemos caracterizar a estratégia argumentativa de 
Berkeley como uma escolha, no sentido de começar pelo fim do processo, isto é, pelo nome - ou, para usar a metáfora sugerida pelo Prof. Taranto, fazendo um "streap tease das idéias". ${ }^{50}$

$\mathrm{O}$ conceito de representação, em Berkeley, não supõe uma duplicação do mundo, ou seja, uma bipartição da realidade entre mundo exterior e interior, material e espiritual, real e aparente, etc. Entretanto, a linguagem pode ser compreendida como uma mediação, que supõe certas etapas no processo de cognição, onde subsiste a tensão entre aparência e realidade. $\mathrm{O}$ modelo da linguagem, em Berkeley, permite opor à relação de causa e efeito uma conjunção de experiências que se organizam em termos de significado e significante. Em contrapartida, o modelo do cálculo geométrico chega à concepção de um mecanismo, que não precisa mais de Deus como hipótese. No modelo apologético supõe-se que entre Deus e nós há uma mediação da linguagem. Desse modo, a proposta de Berkeley não é acreditar na religião porque sim, mas compreender que se trata de uma religião introduzida a partir da fala de Deus - La Grammaire de la Nature —, que admite uma finalidade ou intenção.

Berkeley está inteiramente imerso na tradição do século XVII, para a qual somente Deus é considerado "causa", isto é, Espírito. Qualquer outra modalidade de causação era recebida com desconfiança. Os espíritos (mentes humanas) podiam ser considerados como causa, levando em consideração o seu caráter espiritual e a sua relação com o Espírito Supremo. Para além disso, não podiam estabelecer-se relações de causalidade, mas sim conjunções constantes a partir de uma certa regularidade observada, por exemplo, nos corpos. O ser humano, que tem corpo e também espírito, torna-se um problema. A proposta de Berkeley, porém o dissolve, visto que para ele os corpos 
e todo o mundo material são conjuntos de percepções, idéias na mente do sujeito. Ora, como é que as idéias aparecem? Se não há uma realidade dupla, não pode haver uma teoria causal da percepção, isto é, um objeto material exterior causando a percepção no sujeito em forma de idéias mentais. As percepções aparecem em forma de idéias porque Deus as imprime em nossa mente dessa maneira. Deus imprime em cada um de nós percepções de forma regularmente ordenada, de modo que nós podemos perceber um mundo em comum. Assim, Berkeley concebe a objetividade, pois as idéias não são do espírito humano; são apenas percebidas por ele, mas "causadas" por Deus. A mente humana opera cognitivamente com idéias, porém ontologicamente, só Deus tem o poder de criar ou gerar idéias. O mundo comum é possível porque certas percepções são regularmente conectadas a outras, consolidando uma harmonia entre as diferentes sucessões de percepções de diferentes sujeitos. Se essa harmonia não é logicamente necessária - ou, como quer Leibniz, preestabelecida -, ela torna-se necessária por ser continuamente estabelecida pela Vontade Divina. Deus imprime, em cada um de nós, uma série de percepções que constitui uma linguagem - a Linguagem Divina que nós apreendemos a interpretar. E o mundo físico é, portanto, a compreensão dessa linguagem. 


\section{Bibliografia}

ArIstóteles. Metaphysics / On the soul, in: The works of Aristotle (translated into English under the editorship of W. D. Ross). Chicago: Encyclopædia Britannica, 1952.

Berkeley, G. The Works of George Berkeley Bishop of Cloyne. Edited by A. A. Luce and T. E. Jessop. Nendeln / Liechtenstein: Kraus Reprint, 1979.

Boyle. The origin of forms and qualities, in: Stewart, M. A. (ed.). Selected Philosophical Papers of Robert Boyle. Manchester, 1979.

Brykman, Geneviève. Berkeley: philosophie et apologétique. Paris: Vrin, 1984.

Foster, John \& Robinson, Howard (eds.). Essays on Berkeley: a tercentennial celebration. Oxford: Clarendon, 1985.

Grayling, A. C. Berkeley: The Central Arguments. Illinois: Open Court, 1986.

Grice, H. P. "The causal theory of perception", in: WARNOCK (ed.). The philosophy of perception. Oxford: Oxford University Press, 1967.

Gueroult, Martial. Berkeley: Quatre Études Sur La Perception et sur Dieu. Montaigne: Aubier, 1956.

Kant, Immanuel. Critica da razão pura, in: Os Pensadores. São Paulo: Nova Cultural, 1999.

LEBRUN, Gérard. "Berkeley ou le scéptique malgré lui", in: Manuscrito, XI, 2, Outubro de 1988.

Locke, John. An Essay Concerning Human Understanding (ed. A. C. Fraser). Oxford, 1894. 
Porchat, Oswaldo. "Ação, crença e conhecimento”, in: IV Colóquio de Epistemologia da USJT. São Paulo, 2005.

Tipton, I. C. Berkeley: The Philosophy of Immaterialism. New York \& London: Garland, 1988.

WinkLer, K. Berkeley: An interpretation. Oxford: Clarendon Press, 1994.

ZATERKA, L. "Robert Boyle e John Locke: Hipótese corpuscular e filosofia experimental", in: Circumscribere, Volume 1, 2006, pp. 5866.

Zunino, P. Distância e movimento em Berkeley: a metafísica da percepção. Dissertação de mestrado: FFLCH-USP, 2006.

\section{Notas}

1 "Ser é ser percebido" - Berkeley. Principles, § 3, in: The Works of George Berkeley Bishop of Cloyne. Edited by A. A. Luce and T. E. Jessop. Nendeln / Liechtenstein: Kraus Reprint, 1979.

${ }^{2}$ GraYling. A. C. The Central Arguments. Illinois: Open Court, 1986. 3 "Nada há no intelecto que não tenha estado antes nos sentidos" axioma dos escolásticos (São Tomás), endossado por Berkeley em Philosophical Commentaries - PC, 539, 779.

${ }^{4}$ Cf. Tipton, I. C. Berkeley: the philosophy of imaterialism, VI, iv, p. 201. New York \& London: Garland, 1988.

${ }^{5}$ Berkeley, Principles, $\S 6$.

${ }^{6}$ Locke, J. An Essay Concerning Human Understanding, II, viii, 8, p.169, ed. A. C. Fraser, Oxford, 1894.

${ }^{7}$ Berkeley. Principles, $\S 1$. 
${ }^{8} \mathrm{O}$ problema de saber se estamos acordados ou sonhando pode ser discutido a partir dessa distinção entre realidade (idéias impressas em nossos sentidos por Deus) e imaginação (idéias formadas por nossa vontade a partir das idéias que temos na memória).

${ }^{9}$ Winkler, K. Berkeley: An interpretation. Oxford: Clarendon Press, 1994, p.10.

${ }^{10}$ Berkeley, Principles, $\S 33$.

${ }^{11} \mathrm{Cf}$. Sмith, A. D. "Berkeley's central argument against material substance", p.56, in: Foster and RoBINSON (ed.). Essays on Berkeley. Oxford: Clarendon Press, 1985.

${ }^{12}$ Berkeley. First draft of the Introdution to the Principles, $\S 10$, in: Works.

${ }^{13}$ Berkeley, Principles, $\S 17$.

${ }^{14} \mathrm{Na}$ Introdução dos Principles, Berkeley dirige profundas objeções à concepção lockeana das idéias gerais abstratas.

${ }^{15} \mathrm{Cf}$. Boyle. The origin of forms and qualities, in: Stewart, M. A. (ed.). Selected Philosophical Papers of Robert Boyle. Manchester, 1979, pp.18-53.

${ }^{16}$ Locke. Essay, II, viii, 9-10.

${ }^{17}$ Ibidem, II, viii, 12.

${ }^{18}$ Apesar das controvérsias - que não vamos discutir aqui — adotamos a interpretação mais aceita, isto é, que Locke sustentava uma teoria representativa da percepção. Com base no Essay, IV, iv, 3 e IV, xi, 2, Grayling confirma esse ponto.

${ }^{19}$ Cf. Locke. Essay, IV, iv, 3.

${ }^{20}$ Ibidem, II, viii, 15.

${ }^{21}$ ZATERKA, L. "Robert Boyle e John Locke: Hipótese corpuscular e filosofia experimental', in: Circumscribere, Volume 1, 2006, pp. 5866. 
22 Berkeley, Principles, § 25.

${ }^{23}$ Ibidem, $\S 65$.

${ }^{24}$ Ibidem, $\S \S 8$ e 25.

${ }^{25}$ Ibidem, $\S 10$.

${ }^{26}$ Sobre esse problema, ver BERKELEY. An essay towards a new theory of vision, in: Works. Ver ainda ZUNINO, P. Distância e movimento em Berkeley: a metafisica da percepção. Dissertação de mestrado: FFLCH-USP, 2006.

${ }^{27}$ Cf. Berkeley. Dialogues 1, pp.179-186, in: Works.

${ }^{28} \mathrm{Cf}$. GRICE, H. P. "The causal theory of perception", in: WARNOCK (ed.). The philosophy of perception. Oxford: Oxford University Press, 1967.

${ }^{29}$ Tipton, p. 183.

${ }^{30}$ ARISTÓTELES. On the soul, II, vi, in: The works of Aristotle (translated into English under the editorship of W. D. Ross). Chicago: Encyclopædia Britannica, 1952. Nessa obra, Aristóteles distingue três classes de "objetos dos sentidos": (a) o objeto que pode ser percebido apenas por um único sentido; (b) o objeto que pode ser percebido por qualquer sentido ou por todos eles; (c) o objeto que pode ser percebido incidentalmente. Aristóteles chama de "sensível próprio" (special object) aquele objeto que não pode ser percebido por qualquer outro sentido, tal como a cor, que é o "sensível próprio" da vista; o som do ouvido; o sabor do gosto e assim por diante. Os "sensíveis comuns", por sua vez, podem ser percebidos por dois ou mais sentidos, de sorte que o movimento, o número, a figura e a magnitude não são próprios de nenhum sentido, mas comuns ao tato e à visão. Por último, o objeto incidental é definido a partir do seguinte exemplo: dizemos que vemos "o filho de Diares" ao perceber a parte branca, diretamente vísivel, da sua roupa. Nesse caso, percebemos incidentalmente o filho de Diares. 
Contudo, conclui Aristóteles, não é exatamente assim que o objeto afeta nossos sentidos, portanto "a classe dos sensiveis próprios constitui o objeto dos sentidos no sentido estrito do termo".

${ }^{31}$ GraYling, p77.

${ }^{32}$ Berkeley. Principles, $§ 1$.

${ }^{33}$ Porchat, Oswaldo. IV Colóquio de Epistemologia da USJT: "Ação, crença e conhecimento”. São Paulo, 2005.

${ }^{34}$ Cf. Kant. Crítica da Razão Pura, p.89, in: Os Pensadores. São Paulo: Nova Cultural, 1999.

${ }^{35}$ Gueroult. Berkeley: quatre études sur la perception et sur Dieu. Montaigne: Aubier, 1956, pp.25-28.

${ }^{36}$ BERKELEY. The theory of vision vindicated and explained, $\S \S 9-11$, in: Works.

${ }^{37}$ Cf. Tipton, p.183.

${ }^{38}$ Locke, John. Ensaio acerca do entendimento humano, II, i, 4, p.28, in: Os Pensadores. São Paulo: Nova Cultural, 1991.

${ }^{39}$ Provavelmente, como uma forma de captatio benevolentice. Esta expressão da retórica latina significa literalmente 'conquista da benevolência' e era apresentada no início da obra quando um autor queria ganhar a simpatia do leitor.

${ }^{40}$ Berkeley. Principles, $\S 2$.

${ }^{41}$ Cf. Berkeley. Philosophical Commentaries, 429.

${ }^{42}$ Alguns autores (Ayer, Price) sugerem que o problema estaria na ambigüidade entre "perceber" e "conceber", tendo em vista que é possível imaginar alguma coisa, mesmo sem percebê-la sensivelmente. Mas Berkeley usa esse argumento para mostrar o contrário: "nada mais fácil do que imaginar, por exemplo, árvores em um parque, ou livros em uma estante e ninguém para percebê-los" (Principles, $\S \S$ 22-24). O fato de poder "imaginar" esses objetos como coisas que 
não são "atualmente percebidas" significa que já as estamos percebendo, porém, abstraindo-se o sujeito. Nesse sentido, "imaginar" também é uma forma de perceber que consiste em imaginar-se a si mesmo percebendo. Se perguntarmos a alguém, por exemplo, como seria ver o sistema solar desde o Sol, a pessoa teria que imaginar-se no Sol percebendo os planetas em volta e, abstraindo-se a si mesma do contexto, teria uma resposta possível. Essa discussão reproduz o debate entre os professores Plínio Smith (USJT) e Paulo Faria (UFRGS), após a conferência do Prof. André Klaudat (UFRGS), intitulada: "Confiança nos sentidos", proferida durante o IV Colóquio de Epistemologia da USJT: “Ação, crença e conhecimento”. São Paulo, 2005.

${ }^{43}$ Berkeley. Principles, $§ 27$.

${ }^{44}$ Ibidem, $\S \S 140-142$.

${ }^{45}$ Grayling, p.50.

${ }^{46}$ Berkeley. Principles, $\S 48$.

${ }^{47}$ Ibidem, $\S 148$.

${ }^{48}$ Cf. Tipton. Berkeley: The Philosophy of Immaterialism, p.298.

${ }^{49}$ Berkeley. Principles, $\S 149$.

${ }^{50}$ Cf. Taranto, P. Curso: «George Berkeley: Les Principes de la connaissance humaine », FFLCH-USP, 2006, p. 24 : “Ainsi l'illusion des mots (...), qui consiste à nous faire croire que chaque mot signifiant correspond nécessairement à une idée fixe, et cette idée à une réalité, se trouve-t-elle dissipée. Il faut pour cela « tirer le rideau des mots» (metaphorical dress), et contempler les idées "pures et nues». Car les idées ne représentent rien qu'elles-mêmes; elles n'ont pas de double-fond, ni ne recèlent rien de caché. L'union des mots et des idées doit être dissoute pour permettre au critère de vérification du sens de s'appliquer." 